\title{
Кариосистематическое изучение рода Eranthis Salisb. (Ranunculaceae)
}

\section{Karyosystematic study of the genus Eranthis Salisb. (Ranunculaceae)}

\author{
Митренина Е. Ю. ${ }^{1}$, Эрст А. С. ${ }^{2}$ \\ Mitrenina E. Yu. ${ }^{1}$, Erst A. S. ${ }^{2}$ \\ ${ }^{1}$ Томский государственный университет, г. Томск, Россия. E-mail: emitrenina@gmail.com \\ ${ }^{2}$ Центральный сибирский ботанический сад СО РАН, г. Новосибирск, Россия. E-mail: erst_andrew@yahoo.com \\ ${ }^{1}$ Tomsk State University, Tomsk, Russia \\ ${ }^{2}$ Central Siberian Botanical Garden SB RAS, Novosibirsk, Russia
}

\begin{abstract}
Peфepam. Изучены кариотипы четырех видов рода Eranthis: E. hyemalis, E. lobulata, E. longistipitata и E. stellata. Для E. lobulata и E. longistipitata данное исследование выполнено впервые. Все изученные образцы имели соматическое число хромосом $2 \mathrm{n}=16$. Кариотипы исследованных видов содержат пять пар равноплечих (метацентрических) хромосом и три пары неравноплечих (субметацентрических, субтелоцентрических, телоцентрических) хромосом. Основное различие хромосомных наборов данных видов заключается в типах неравноплечих хромосом. Различия в кариоморфологических параметрах у изученных видов согласуются с разделением рода на секции по морфологическим признакам.
\end{abstract}

Ключевые слова. Кариотип, кариосистематика, хромосомы, Eranthis, Ranunculaceae.

Summary. Karyotypes of four species of the genus Eranthis: E. hyemalis, E. lobulata, E. longistipitata and E. stellata were investigated. The study of $E$. lobulata and $E$. longistipitata has been implemented for the first time. All studied specimen had somatic chromosome number $2 n=16$. Karyotypes of investigated species have five pairs of chromosomes with equal-sized arms (metacentric chromosomes), and three pair of chromosomes with unequal-sized arms (submetacentric, subtelocentric, telocentric chromosomes). The chromosome complements of investigated species basically differ in types of chromosomes with unequal-sized arms. Karyomorphological differences of the species are relevant to the genus subdivision into sections regarding to morphological characteristics.

Key words. Chromosomes, Eranthis, karyotype, karyosystematics, Ranunculaceae.

\section{Введение}

Род Eranthis Salisb. характеризуется клубневидно утолщенными подземными стеблями, пальчато-раздельными базальными листьями, безлистным стеблем, несущим на верхушке листовидную обертку, актиноморфными одиночными цветками с необычным строением лепестков (Tamura, 1990). Это небольшой, но таксономически сложный род трибы Eranthideae T. Duncan et Keener (Ranunculaceae Juss.), до недавнего времени включавший восемь видов (Tamura, 1990; Mabberley, 1993). Недавно были описаны два новых вида из Кореи - E. byunsanensis B. Y. Sun и E. pungdoensis B. U. Oh (Sun et al., 1993; $\mathrm{Oh}, \mathrm{Ji}, 2009)$. Таким образом, в настоящее время род включает 10 видов, распространенных в умеренных регионах Евразии (Li, 1995; Wang et al., 2001). E. hyemalis Salisb., изначально распространённый в Европе, был завезён в Северную Америку, где сейчас встречается в дикой природе (Parfit, 1997). Таксономический статус E. cilicica Schott et Kotschy из Турции и E. bulgarica (Stef.) Stef. из Болгарии требует уточнения с привлечением комплекса методов. Согласно базе данных The International Plant Names Index, этот род включает 15 видов и 5 внутривидовых таксонов, синонимика некоторых видов не выяснена. Таким образом, информация, касающаяся видового состава рода Eranthis очень разрозненна и противоречива. 
Цитогенетические исследования широко применяются как один из подходов для решения вопросов систематики и эволюции растений, в том числе и семейства Ranunculaceae (Yuan, Yang, 2006; Baltisberger, Hörandl, 2016). Однако род Eranthis почти не изучен в этом отношении. Согласно базам данных Chromosome Counts Database (Rice et al., 2015), Index to Plant Chromosome Numbers, Plant DNA C-value Database и научным публикациям, не включенным в данные базы, числа хромосом установлены только для половины известных в настоящее время видов. Для рода выявлены основные числа хромосом $x=7$ (E. stellata Maxim.) и $x=8$ (E. cilicica, E. hyemalis, E. pinnatifida Maxim., E. sibirica DC., E. stellata). В основном, для Eranthis характерны диплоидные цитотипы с 2 n $=16$, но также встречаются полиплоидные формы. Так, для E. hyemalis помимо диплоидов выявлены триплоиды с $2 \mathrm{n}=24$ и гексаплоиды с 2n $=48$ (Rice et al., 2015), для E. sibirica - тетраплоиды с 2n $=32$ (Чепинога, 2014). Хромосомные наборы описаны только для двух видов: E. hyemalis (Gömürgen, 1997) и E. stellata (Yuan, Yang, 2006). Изучение кариотипов представителей данного рода может дать ценную информацию для понимания систематических и эволюционных отношений в данном таксоне.

\section{Материал и методы}

Для анализа кариотипов проращивали семена E. hyemalis и E. longistipitata, клубни E. stellata и E. lobulata. Данные о происхождении материала представлены в таблице. Препараты готовили из корневой апикальной меристемы по методу Смирнова (1968). Для накопления клеток на стадии метафазы использовали предобработку корней длиной 1-2 см 0,2 \% раствором колхицина, а затем помещали их в фиксатор Кларка. Клетки корневой меристемы окрашивали ацетогематоксилином. Анализ и фотосъемку метафазных пластинок проводили на микроскопе AxioImager A.1 (Carl Zeiss, Germany) с ПО AxioVision 4.7 (Carl Zeiss, Germany) и CCD-камерой AxioCam MRc5 (Carl Zeiss, Germany) при увеличении $\times 1000$. Для кариотипирования использовали ПО KaryoType (Altinordu et al., 2016), для подготовки иллюстраций - ПО Adobe Photoshop CS5 (Adobe Systems, USA) и Inkscape 0.92 (USA). Морфологический тип хромосом определяли согласно классификации Levan et al. (1964).

Таблица

Характеристика кариотипов изученных видов рода Eranthis

\begin{tabular}{|l|c|c|c|c|}
\hline \multicolumn{1}{|c|}{ Вид } & $\begin{array}{c}\text { Происхождение } \\
\text { образцов }\end{array}$ & Формула кариотипа & $\begin{array}{c}\text { Средняя } \\
\text { тотальная длина } \\
\text { гаплоидного } \\
\text { набора, мкм }\end{array}$ & $\begin{array}{c}\text { Индекс } \\
\text { асимметрии } \\
\text { (Stebbins, } \\
1971)\end{array}$ \\
\hline E. hyemalis & $\begin{array}{c}\text { Россия, Санкт-Петербург, } \\
2017\end{array}$ & $\begin{array}{c}2 \mathrm{n}=16=10 \mathrm{~m}+2 \mathrm{sm}+ \\
2 \mathrm{st}+2 \mathrm{~s}^{\mathrm{sat}}\end{array}$ & $57,60 \pm 2,68$ & $2 \mathrm{~B}$ \\
\hline E. lobulata & Китай, Сычуань, 2018 & $\begin{array}{c}2 \mathrm{n}=16=10 \mathrm{~m}+2 \mathrm{sm}^{\mathrm{sat}}+ \\
2 \mathrm{st}+2 \mathrm{t}+0-1 \mathrm{~B}\end{array}$ & $55,62 \pm 1,89$ & $2 \mathrm{~A}$ \\
\hline E. longistipitata & Казахстан, Джамбул, 2018 & $\begin{array}{c}2 \mathrm{n}=16=10 \mathrm{~m}+2 \mathrm{sm}+ \\
2 \mathrm{st}+2 \mathrm{st}^{\mathrm{sat}}\end{array}$ & $45,77 \pm 2,92$ & $2 \mathrm{~B}$ \\
\hline E. stellata & Россия, Владивосток, 2018 & $\begin{array}{c}2 \mathrm{n}=16=10 \mathrm{~m}+2 \mathrm{sm}+ \\
2 \mathrm{sm}^{\text {sat }}+2 \mathrm{t}\end{array}$ & $61,11 \pm 2,22$ & $2 \mathrm{~B}$ \\
\hline
\end{tabular}

Примечания: $2 \mathrm{n}$ - соматическое число хромосом; $\mathrm{m}$ - метацентрик; sm - субметацентрик; st - субтелоцентрик; t - телоцентрик; B - добавочная В-хромосома; sat - наличие вторичной перетяжки у данной пары хромосом; мкм - микрометры.

\section{Результаты и обсуждение}

Нами изучены кариотипы Eranthis hyemalis, E. lobulata, E. longistipitata и E. stellata. Bce исследованные растения являлись диплоидными с $2 \mathrm{n}=16$ (рис. 1). Полученные нами результаты демонстрируют сходство кариотипов у изученных видов эрантисов: пять пар хромосом являются равноплечими (метацентрическими), три пары - неравноплечими (субметацентрическими, субтелоцентрическими, телоцентрическими). Формулы кариотипов представлены в таблице. Основные различия хромосомных наборов касаются морфологии неравноплечих хромосом (рис. 2). Для E. lobulata и E. stellata характерно присутствие в кариотипе пары «одноплечих» (телоцентрических) хромосом. Хромосомные набо- 
ры E. hyemalis и E. longistipitata представлены исключительно двуплечими хромосомами. Полученные нами формулы кариотипов двух последних видов одинаковы. Однако их хромосомные наборы различаются по размеру субметацентриков, центромерному индексу субтелоцентриков, а также по тотальной длине гаплоидного набора хромосом. У E. lobulata в некоторых клетках корневой меристемы выявлены небольшие одиночные метацентрические В-хромосомы. Длина добавочной хромосомы составляет примерно 5 \% от тотальной длины гаплоидного набора хромосом данного вида. Наличие В-хромосом для рода Eranthis выявлено нами впервые.

Нами установлено, что для всех изученных видов характерно наличие вторичной перетяжки на коротком плече одной из пар неравноплечих хромосом. Ее положение варьирует в зависимости от вида. У E. lobulata и E. stellata она локализуется в коротком плече у пары субметацентриков: на расстоянии около трети длины плеча от центромеры у E. lobulata и около трети длины плеча от терминального рай-
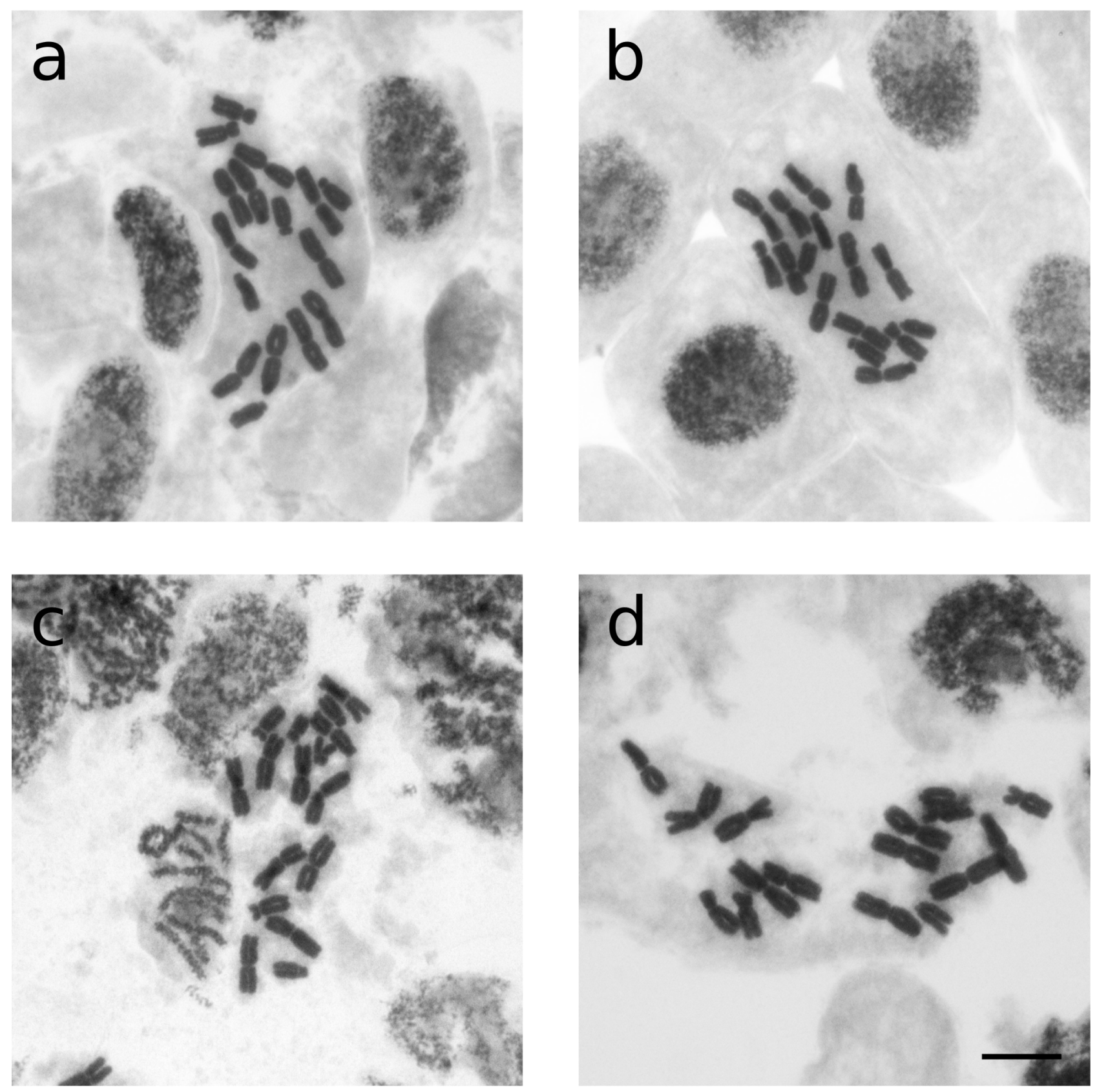

Рис. 1. Метафазные митотические хромосомы: a - Eranthis hyemalis, $2 \mathrm{n}=16 ; \mathrm{b}-$ Eranthis lobulata, $2 \mathrm{n}=16+0-1 \mathrm{~B}$; $\mathrm{c}-$ Eranthis longistipitata, $2 \mathrm{n}=16 ; \mathrm{d}-$ Eranthis stellata, $2 \mathrm{n}=16$. Шкала -10 мкм. 
она у E. stellata. Таким образом, ее расположение является «зеркальным» у этих близких видов. Возможно, такая локализация вторичных перетяжек связана с небольшой парацентрической инверсией, произошедшей в процессе видообразования. У E. hyemalis и E. longistipitata вторичная перетяжка находится в коротком плече у пары субтелоцентриков, также занимая разное положение. Для E. hyemalis характерно ее дистальная локализация, для E. longistipitata - проксимальная.

Наши результаты по числу, размеру и морфологии хромосом эрантисов частично согласуются с известными нам данными других исследователей. Gömürgen (1997) был описан кариотип E. hyemalis из Турции: $2 \mathrm{n}=16=12 \mathrm{~m}+4 \mathrm{sm}$. Эти результаты не полностью соответствуют нашим. Мы предполагаем, что в приведенной работе был изучен кариотип E. cilicica, поскольку по современным представлениям в данном регионе произрастает именно этот вид. Yuan и Yang (2006) исследовали кариотип E. stellata, определив его формулу как $2 \mathrm{n}=16=10 \mathrm{~m}+2 \mathrm{sm}+2 \mathrm{st}+2 \mathrm{~T}$. Она отличается от наших результатов морфологическим типом одной пары хромосом. Поскольку в работе этих авторов не представлены морфометрические характеристики кариотипа, нет возможности оценить, насколько они соответствуют нашим данным.

Таким образом, нами показаны различия хромосомных наборов у четырех изученных видов эрантисов: E. hyemalis, E. lobulata, E. longistipitata и E. stellata. Однако по ряду морфологических характеристик хромосом выявлено сходство кариотипов у E. lobulata c E. stellata, у E. hyemalis с E. longistipitata. Кариоморфологические особенности у изученных видов согласуются с разделением рода на секции по морфологическим характеристикам. E. lobulata и E. stellata входят в секцию Shibateranthis (Nakai) Tamura, характеризующуюся белыми цветками и сферическими клубневидными подземными органами, а E. hyemalis и E. longistipitata входят в типовую секцию Eranthis, характеризующуюся желтыми цветками и вытянутым клубневидным корневищем.

Благодарности. Исследование выполнено при финансовой поддержке РФФИ в рамках научного проекта № 18-34-20056 мол_а_вед, Программ №AААА-А17-117012610055-3 Центрального Сибирского ботанического сада СО РӒН и повышения конкурентоспособности Томского государственного университета № 8.1.09.2018. Авторы выражают благодарность Анненкову Р. В. (НИ ТГУ, ИПМКН) за подготовку иллюстраций.

a

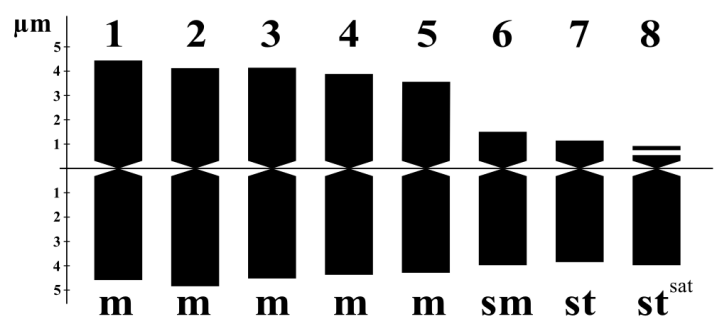

b
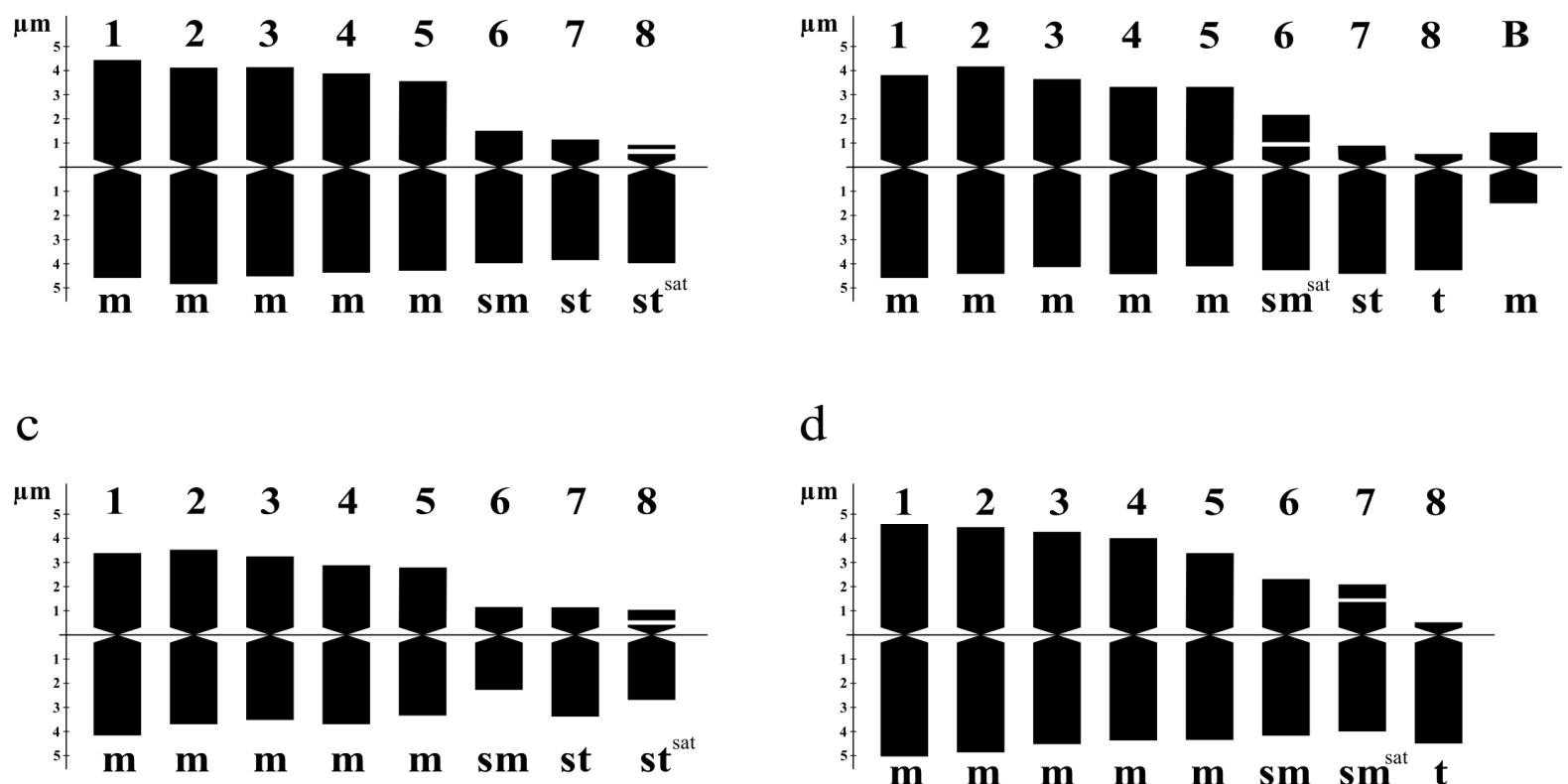

d

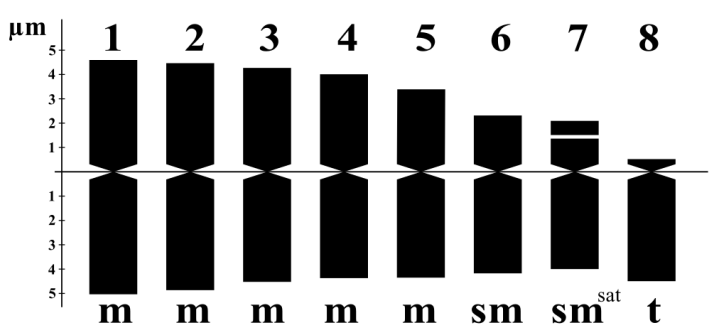

Рис. 2. Идиограммы: a-Eranthis hyemalis, $2 \mathrm{n}=16 ; \mathrm{b}-$ Eranthis lobulata, $2 \mathrm{n}=16+0-1 \mathrm{~B} ; \mathrm{c}-$ Eranthis longistipitata, $2 \mathrm{n}=16 ; \mathrm{d}-$ Eranthis stellata, $2 \mathrm{n}=16$. Условные обозначения: $1-8-$ порядковый номер пары хромосом; $\mathrm{m}-$ метацентрик; sm - субметацентрик; st - субтелоцентрик; $\mathrm{t}$ - телоцентрик; В - добавочная B-хромосома; sat - наличие вторичной перетяжки у данной пары хромосом; $\mu \mathrm{m}$ - микрометры. 


\section{ЛИТЕРАТУРА}

Смирнов Ю. А. Ускоренный метод исследования соматических хромосом плодовых // Цитология, 1968. - Т. 10, № 12. - С. 1601-1602.

Чепинога В. В. Хромосомные числа растений флоры Байкальской Сибири. - Новосибирск: Наука, 2014. $419 \mathrm{c}$

Altinordu F., Peruzzi L., Үи Y., Не X. A tool for the analysis of chromosomes: KaryoType // Taxon, 2016. - V. 65, № 3. - P. 586-592.

Baltisberger M., Hörandl E. Karyotype evolution supports the molecular phylogeny in the genus Ranunculus

(Ranunculaceae) //Perspectives in Plant Ecology, Evolution and Systematics, 2016. - V. 18. - P. 1-14.

Gömürgen A. N. Chromosome numbers and karyotype analysis of Eranthis hyemalis (L.) Salisb. // Progress in botanical research. Proceedings of the 1st Balkan Botanical Congress. / Tsekos I, Moustakas M, eds. - Dordrecht: Kluwer Academic Publishers, 1997. - P. 489-492.

Index to Plant Chromosome Numbers (IPCN) IPCN. URL: https://www.tropicos.org/Project/IPCN (дата обращения 01.03.2019)

Levan A., Fredgam K., Sandberg A. Nomenclature for centrometric position of chromosomes // Hereditas, 1964. V. - 52. - P. 201-220.

Li L. Q. The geographical distribution of Subfam. Helleboroideae (Ranunculaceae) // Acta Phytotaxonomica Sinica, 1995. - V. 33. - P. 537-555.

Mabberley D. J. The plant-book. - Cambridge University Press, New York, 1997. - 858 p.

Oh B. U., Ji S. J. Eranthis pungdoensis B. U. Oh: a new species of Eranthis (Ranunculaceae) from Korea // Korean Journal of Plant Taxonomy, 2009. - V. 39. - P. 86-88.

Parfitt B. D. "Eranthis" in Flora of North America, FNA. Provisional Publication. Flora of North America Association, 2009. - V. 3. URL: http://www.efloras.org/florataxon.aspx?flora_id=1\&taxon_id=111902 (дата обращения 25.02.2019)

Plant DNA C-values Database http://data.kew.org/cvalues/ (дата обращения 01.03.2019).

Rice A., Glick L., Abadi Sh., Einhorn M., Kopelman N. M., Salman-Minkov A., Mayzel J., Chay O., Mayrose I. The Chromosome Counts Database (CCDB) - a community resource of plant chromosome numbers // New Phytologist, 2015. - V. 206, № 1. - P. 19-26. URL: http://ccdb.tau.ac.il/ (дата обращения 01.03.2019)

Stebbins G. L. Chromosomal evolution in higher plants. - London: Arnold. 1971. - 216 p.

Sun B. Y., Kim C. H., Kim T. J. A new species of Eranthis (Ranunculaceae) from Korea: E. byunsanensis // Korean Journal of Plant Taxonomy, 1993. - V. 23. - P. 21-26.

Tamura M. A new classification of the family Ranunculaceae 1 // Acta Phytotaxonomica et Geobotanica, 1990. - V. 41. - P. 93-101.

The International Plant Names Index (IPNI) URL: http://ipni.org/ (дата обращения 01.03.2019).

Wang W., Fu D., Li L., Bartholomew B., Brach A. R., Dutton B. E., Gilbert M. G., Kadota Y.,. Robinson O. R., Tamura M., Warnock M. J., Zhu G., Ziman S. N. Ranunculaceae // Flora of China / Raven P. H., Wu Z.-Y. (eds). - Science Press and Missouri Botanical Garden Press, Beijing China, St. Louis, MO, USA, 2001. - V. 6. - P. $133-438$.

Yuan Q., Yang Q.-E. Tribal relationships of Beesia, Eranthis and seven other genera of Ranunculaceae: evidence from cytological characters // Botanical Journal of the Linnean Society, 2006. - V. 150. - P. 267-289. 